\title{
VISIONES SOBRE LA SOCIOLOGÍA ESPAÑOLA: HACIA LAS NARRATIVAS ABIERTAS Y SACERDOTALES ${ }^{1}$
}

\author{
Alberto J. Ribes Leiva \\ Universidad Complutense de Madrid
}

\begin{abstract}
Resumen.- En este texto se explora la forma de narrar la historia de la sociología española. Partiendo de Levine, se trata de hacer una sociología de la historia/sociología de la sociología, o una sociología de tercer nivel. En este empeño se identifican una serie de formas de narrativas históricamente existentes así como las formas de narración posibles. Por último se reflexiona sobre algunas paradojas que pueblan la bibliografía sobre la sociología española.
\end{abstract}

Palabras clave.- sociología española; sociología de la sociología; historia de la sociología; teoría sociológica; narrativas

\begin{abstract}
In this article I explore the narratives of the History of Spanish Sociology. Following Levine's suggestion, a sociology of the history/sociology of sociology, or a third level sociology, is presented. A number of actually existing narratives and possible narratives ares identified. At the end of the article I deal with some paradox which are usually present in the narratives of the history of Spanish Sociology.
\end{abstract}

Key words.- spanish sociology; sociology of sociology; history of sociology; sociological theory; narratives

\section{Introducción: Levine y las narrativas sobre la historia de la sociología}

Donald N. Levine publicó hace ya algunos años su original aportación al estudio de la tradición sociológica, Visions of the sociological tradition ${ }^{2} \mathrm{La}$ primera parte de esta obra, Levine la consagra al análisis de las narrativas que nos cuentan la historia de la disciplina, estableciendo, a tal fin, un recuento de modos diversos de concebir la disciplina sociológica vinculados a modos diversos de entender e interpretar su historia. Parte Levine (1995: 11) de la

\footnotetext{
${ }^{1}$ Este trabajo forma parte del proyecto colectivo sobre la historia de la sociología española que está llevando a cabo el Grupo de Investigación de la UCM "Sociología en lengua castellana: perspectiva histórica". En cualquier caso, el análisis aquí presentado es responsabilidad exclusiva del autor que lo firma. Presenté una primera versión del texto en el X Congreso Español de Sociología, organizado por la Federación Española de Sociología, que tuvo lugar en Pamplona, en Julio de 2010.

${ }^{2}$ Sobre este texto pueden verse Rodríguez Ibáñez (2008).
} 
constatación del hecho de que las historias internas de las disciplinas científicas sirven para legitimar paradigmas existentes previamente o nuevos paradigmas emergentes. De este modo, las historias de la sociología son, además de lo que su propio enunciado indica, también y quizá más fundamentalmente reivindicaciones temporal, espacial y paradigmáticamente situadas.

Los seis tipos de narrativa y los autores centrales señalados por Levine son los siguientes: positivista (Comte, Park y Burguess), pluralista (Sorokin, Martindale, Eisenstadt), sintética (Parsons, Alexander, Habermas), humanística (Nisbet, Aron, Coser), contextualista (Zeitlin, Gouldner, Friedrichs, Lepenies) y dialógica (Levine). Veamos, brevemente, las principales líneas de cada una de estas narrativas.

Las narrativas positivistas se caracterizan por compartir los siguientes rasgos: se consideran las organizaciones sociales como un fenómeno natural investigable con los métodos de las ciencias naturales, una concepción acumulativa y progresiva de la actividad científica, una búsqueda de leyes generales, empíricamente respaldadas, que puede permitir a los humanos solucionar problemas prácticos, y, por último, una disputa contra el pensamiento subjetivo mediante una estrategia de rigor empírico y coherencia teórica. Como ejemplos representativos de las narrativas positivistas cita Levine a Comte y a Park y Burguess.

Las narrativas pluralistas se caracterizan por asumir que el desarrollo de la sociología ha tomado su forma de una evolución de divergentes enfoques teóricos y agendas de investigación. Desde este enfoque se considera que dichas diferencias van a perdurar. Los periodos de crecimiento son intermitentes, y se alternan con periodos de estancamiento de regresión o de crisis. Este tipo de narrativa la han practicado, a juicio de Levine, Sorokin, Don Martindale o Ritzer.

Las narrativas sintéticas consideran que las formulaciones teóricas son tan importantes como las técnicas de investigación para el avance de la sociología. La teoría sociológica, según estas versiones, se organizó, en sus comienzos, en distintas escuelas que competían entre ellas. La perspectiva del presente desde el cual se escriben estas historias de la sociología permite a sus practicantes considerar que todas estas escuelas tenían parcialmente razón y han contribuido a la mejora y el avance de la disciplina. Estas escuelas de los inicios de la sociología son consideradas riachuelos que desembocan en el gran río de la sociología presente. Los autores que ejemplifican esta línea son Parsons, Alexander y Habermas.

Las narrativas contextualistas (entre las destaca nuestro autor aquellas elaboradas por Gouldner, Friedrichs, Levine, Zeitlin o Lukács) prestan, en comparación con las demás, poca atención al contenido substantivo de las producciones sociológicas. Es la línea de los trabajos bien de la tradición de la sociología de la sociología (Gouldner, Friedrichs), bien de los autores que enfatizan el peso de la historia y de la estructura social en el desarrollo de la sociología (Zeitlin, Lukács).

Todas estas narrativas deberían ser superadas por un modelo de narrativa dialógica. La propuesta fundamental de Levine para una sociología de la sociología se basa en estudiar la tradición sociológica de un modo dialógico, es 
decir, teniendo en cuenta los distintos diálogos que se establecen entre los distintos teóricos sociales que son reconocidos como propios dentro de la tradición sociológica (Levine, 1995: 95-100). Según señala Levine, la fragmentaria y anómica visión de la sociología debe ser aliviada mediante el esfuerzo de recuperar la tradición sociológica, no estableciendo un conjunto común de conocimientos para todos sino reconociendo que las múltiples ramas de la sociología descienden de los participantes en una conversación común (Cfr. Levine, 1995: 95-96).

Esta forma indirecta de acceso al conocimiento de la tradición sociológica parece sumamente oportuna, por lo que planteo en estas páginas aproximarme a una clasificación de narrativas sobre la sociología española siguiendo libremente la propuesta de Levine, y adaptándola al caso español específico que exige no pocas modificaciones. Este giro hacia una sociología de la historia/sociología de la sociología, hacia una sociología de la sociología de tercer orden puede $^{3}$, a mi juicio, arrojar algunos nuevos frutos a esta subdisciplina ${ }^{4}$ y al campo de los estudios sobre la sociología española.

\section{Dimensiones básicas de los espacios para la narración}

En mi formulación original de este problema (Ribes, 2005: 107-119) distinguía dentro de las narrativas disponibles sobre la sociología española entre narrativas anti-clasicistas 0 presentistas, narrativas institucionalistas y narrativas inclusivas. En aquel momento, presentaba críticamente a las dos primeras mientras que abogaba por el tipo de narrativa inclusiva desde el que escribí mi revisión de la sociología española (Ribes, 2005 y 2007) y mis trabajos sobre la sociología de Ayala (Ribes, 2007), de Medina (Ribes, 200) y Recaséns Siches (Ribes, 2008b). No obstante, me parece ahora más adecuado y completo cruzar las dimensiones anti-clasicismo, institucionalimo, inclusivismo con otras dimensiones tales como fuerte/débil imperialismo paradigmático y fuerte/débil autonomización del campo sociológico español.

Con fuerte/débil imperialismo paradigmático me refiero a la posición del narrador en cuanto a su concepción de la disciplina. Sucede en muchas ocasiones que los narradores de la sociología española relatan su historia desde una definición muy concreta de sociología, lo que expulsa de la disciplina a todas las manifestaciones que no encajan en dicha definición. La tentación débil de una imposición paradigmática vertida sobre la historia de la disciplina ocupa el otro extremo del continuo.

Por fuerte/débil autonomización del campo sociológico español entiendo las posiciones que van desde la mera consideración de factores internos a la historia de la disciplina a la consideración fundamental de factores externos a la hora de explicar el desarrollo de la sociología. En la bibliografía de la sociología

\footnotetext{
${ }^{3}$ Sobre sociología de la sociología pueden verse Torres Alberto (1994 y 2002) y Ribes Leiva (2008).

En España, un primer paso hacia esta dirección lo dio Zarco (1999: 130-135) con su propuesta de "las tres historias de la sociología española". El segundo paso fue el proyecto de reunir en un volumen las principales narraciones sobre la sociología española. Dicho proyecto en el que colaboramos Cristóbal Torres, Héctor Romero y el autor de estas páginas está todavía pendiente de realización. Un tercer paso lo dio el autor de estas páginas como se detallará más adelante.
} 
española se suele entender por factores externos a dos elementos: por un lado, para la "Generación de la guerra" el factor esencial y determinante que explica tanto sus propias vocación hacia la sociología, así como el desarrollo y el desenvolvimiento de la disciplina es la crisis; para la "Generación de 1959" (Rodríguez lbáñez, 2011), el factor externo clave es la modernidad.

Cruzando las dimensiones mencionadas resultarán una serie de espacios narrativos posibles que han sido o pueden ser transitados por las narrativas sobre la sociología española. Así podemos hablar de narrativas egocéntricas, proféticas, progresistas, teleológicas, con final feliz, abiertas y sacerdotales.

A esta clasificación de tipos de narrativas habría que sumarle una dimensión transversal que es la dimensión paradójica presente en buena parte de las narrativas disponibles sobre la sociología española. Esta dimensión consiste básicamente en hacer una historia de la disciplina sociológica en España en la que se concluye que no hubo, en sentido estricto, sociología en España. Me ocuparé al final de este texto de dicha condición, dado que parece ser un denominador común de este tipo de trabajos.

Por otro lado, es preciso advertir que esta clasificación de tipos de narrativas está construida bajo la asunción de la posibilidad de que las categorías narrativas aquí esbozadas no sean auto-excluyentes. Aunque algunas sí son incompatibles, son posibles varios juegos y combinaciones entre otras. Podríamos, por ejemplo, pensar en narrativas proféticas-con final feliz o narrativas sacerdotales-con final feliz. De una forma más suave se podría hablar de dimensiones egocéntricas dentro de una narrativa progresista, etc. Se trata, por tanto, de espacios típico-ideales de lo posible, que pretenden recoger, como tales, a las narrativas publicadas sobre la sociología española y las posibles narrativas que pueden emerger en el futuro más inmediato (considerando para esto último, el estado actual de este tipo de estudios).

Cuadro 1: Narrativas de la historia de la sociología española

\begin{tabular}{|l|c|c|c|}
\hline & Anti-clasicismo & Inclusivas \\
\hline Fuerte IP/Fuerte ACS & Egocéntricas & ------ & - ------ \\
\hline Fuerte IP / Débil ACS & Proféticas & ----- & ----- \\
\hline Débil IP / Fuerte ACS & Progresistas & ------ & Abiertas \\
\hline Débil IP / Débil ACS & Teleológicas & Final feliz & Sacerdotales \\
\hline
\end{tabular}

IP: Imperialismo paradigmático. ACS: Autonomización del campo sociológico. 


\section{El futuro ya está aquí: : narrativas egocéntricas, proféticas, progresistas y teleológicas}

Las narrativas egocéntricas se componen de la combinación de la dimensión anti-clasicista junto con un fuerte imperialismo paradigmático y junto a una consideración fuerte de la autonomización del campo sociológico español. De este modo, la historia que se presenta es la narración de los precedentes, de los precursores que, en el mejor de los casos, han hecho posible el desarrollo de la disciplina hasta el presente. Según estas narrativas la sociología auténtica está justo naciendo en el presente, normalmente gracias al trabajo de los autores que elaboran la narrativa. Una definición particular de sociología, la definición propia del grupo que narra, se impone arrojando al margen de lo nosociológico o no-del-todo-sociológico todo lo que no encaje con la propia definición de la disciplina. Así tenemos, al mismo tiempo, una búsqueda de precursores que serán considerados, en todo caso, como precedentes, como ensayos previos, parcialmente acertados pero desarrollados de manera insuficiente; y, por otro lado, el resto de las obras y escuelas arrojados al margen de lo no-sociológico. La tercera dimensión (fuerte autonomización del campo sociológico español) apunta a la escasa consideración del peso de otros factores externos al campo en la narración de la disciplina. Lo que interesa a los autores que escriben desde esta narrativa es el análisis de las obras, y su examen para ver si son o no suficientemente sociológicas, resultando siempre en la constatación de que no lo son del todo. Así, la sociología desde este tipo de narrativa se explica como el desarrollo de un paradigma que por fin va a desarrollarse desde el presente. La ventaja de estas narrativas es que anuncian un futuro lleno de auténtica sociología. Es la utopía de la sociología definitiva que será capaz, por fin, de ofrecer conocimientos valiosos sobre la sociedad. Las narrativas egocéntricas ni dan valor a los demás paradigmas, ni otorgan demasiada importancia al propio pasado de su propia tradición paradigmática. Su orientación hacia el futuro las hace seductoras en tanto que nuevos programas o agendas de investigación.

Las narrativas proféticas comparten algunos de los principios señalados en las narrativas egocéntricas. Así, tienen iguales dosis de anti-clasicismo (menosprecio del pasado, orientación hacia el futuro), iguales dosis también de imperialismo paradigmático (menosprecio de otras opciones paradigmáticas), pero se distinguen de las primeras por la inclusión de factores externos en el desarrollo de la disciplina sociológica. La historia que se narra incorpora otros elementos, como la ecuación sociología-modernidad, lo que resulta en una narrativa que nos cuenta la historia inevitable del triunfo de una forma concreta de hacer y entender sociología. De este modo argumentos del tipo, "como no había modernidad no podía haber sociología", arrojan al terreno de lo presociológico o transfieren a otras disciplinas (filosofía social, ensayismo, etc.) el trabajo previo, incluso el de los precursores dentro del propio paradigma. Este tipo de narrativa, es el típico de la segunda mitad del siglo XX.

Veamos algunos casos de manifestaciones de este tipo de narrativa, dada su importancia histórica. Afirma Amando de Miguel, en su Sociología o subversión, que en España no ha habido sociología (ni modernidad) hasta 1959, es decir,

\footnotetext{
${ }^{5}$ Tomo prestado el título del libro de Héctor Fouce sobre La Movida (El futuro ya está aquí. Velecío Editores).
} 
hasta Arboleya y sus discípulos. "Hasta entonces no tiene mucho sentido hablar de Sociología y sociólogos en nuestro país, como resulta prematuro hablar de economía moderna o de sociedad mínimamente industrializada" (de Miguel, 1974: 66). Su argumento se basa en el desarrollo conjunto de sociología y modernidad. Debido a que la sociología sólo surge o sólo puede surgir en una sociedad moderna e industrializada, no ha podido haber, como de hecho no ha habido, en su opinión, sociología en nuestro país ${ }^{6}$. Así, incluso la discusión sobre la cuestión carece de significado porque si no hubo sociología es porque no podía haberla ${ }^{7}$. Y esto es así porque: "La Sociología nace de una élite intelectual en un medio burgués. Es la ausencia de una burguesía secularizada y poderosa lo que incapacita la penetración de la Sociología en la España de comienzos de este siglo" (de Miguel, 1974: 63).

Desde esta perspectiva, la tradición sociológica española carecería de interés y de consistencia (si no de existencia). Los sociólogos que él denomina "Regeneracionistas" (y en esta lista incluye a Aznar, Posada, Sales y Ferré, Azcárate y Costa) se limitan a exponer la sociología que sí se hacía en otros países, o en todo caso aventuraban ciertas ideas de escaso valor ${ }^{8}$. Además, la situación empeora con los años, y sólo se destaca a Ortega, a pesar de que su actitud es "no empírica y no especializada" (de Miguel, 1974: 35), hasta la década de los 40, que es "de casi total esterilidad sociológica" (de Miguel, 1974: 36).

Lo que subyace tras esta manera de entender la historia de la sociología española son tres cuestiones: 1, el perfecto ejemplo de la narrativa anticlasicista o presentista, ya que solamente se retrocede al pasado más inmediato, y se hace con cierta condescendencia, hasta que por fin aparece la sociología unos pocos años antes de la redacción de este mismo libro; 2, un fuerte imperialismo paradigmático; y 3 , una manera específica de entender la historia de España.

Nos vamos a ocupar, en primer lugar, de la tentación paradigmática, del modo peculiar de entender la sociología, que aquí entra en juego, y las implicaciones que tiene en la concepción de la sociología, en la definición de qué es "sociología". Así, lo que el autor sugiere, aunque no lo dice de un modo claro, es que la sociología empírica de corte anglosajón no se importa a España hasta los años sesenta. Incluso este punto es discutible ${ }^{9}$, pero aunque lo aceptáramos, eso no significa que no hubiese (y que no haya) otras

\footnotetext{
${ }^{6}$ Sin embargo, el caso de Inglaterra parece desmentir esta hipótesis, puesto que la inglesa era una sociedad indiscutiblemente moderna, y, sin embargo, la sociología tuvo muchas dificultades para institucionalizarse. Las razones de la relativa tardanza de la institucionalización en Inglaterra las ha estudiado Seffer, y de entre ellas destacamos: la ausencia de una incisiva crítica social, la inexistencia de una teoría sociológica que fuera capaz de explicar los sucesos sociales, la ausencia de líderes intelectuales, la equivocada sociología de Hobhouse y Ginsberg, y la incapacidad para lograr persuadir a los intelectuales, al Estado y a la posible clientela de los beneficios de la sociología. Cfr. Reba N. Seffer, (1982: 767-802).

7 "La discusión sobre si hubo o no Sociología en la España de la Restauración es bastante huera: no podía haberla" (de Miguel, 1974: 63).

${ }^{8}$ Dice de estos sociólogos: "jamás pasaron de una mediocre exposición de la Sociología tal y como se practicaba en otros países, de un mimético organicismo krausista escasamente prometedor, o de una aplicación inimaginativa de ciertas ideas sociológicas básicas en los problemas "sociales" del momento." (de Miguel, 1974: 30).

${ }^{9}$ Véanse Romero Ramos (2004) y Ribes Leiva (2005).
} 
sociologías; que no existiesen otras sociologías con otras influencias y otros modos de ser.

En un epígrafe titulado "La sociología establecida o el empirismo académico" dice el mismo autor: "Los tiempos del humanismo ensayista han pasado. El auge de la moderna Sociología española se debe sobre todo a la recepción de la mentalidad anglosajona que considera a la Sociología una ciencia y una actividad universitaria y que se vuelve hacia la observación sistemática de la realidad con métodos propios" (de Miguel, 1974: 96). De este modo, se afirma que hasta la llegada de la sociología empírica moderna no había sino "humanismo ensayista", y desde luego no sociología. Ya no se discute la calidad, la relevancia o la difusión de unos autores, de unas teorías o de unas ideas, sino que se niega la propia existencia de la sociología. No habría, según estas hipótesis, "realmente sociología".

En el libro colectivo Sociología española de los años 70 (Cfr. VVAA, 1971) se sostiene una tesis similar a la de Amando de Miguel. En un capítulo introductorio se afirma que "la sociología en nuestro país está en sus comienzos" ${ }^{10}$, refiriéndose a los años 70. En el cuadro Estructura de la profesión sociológica en España (páginas 18-19) destacan más las ausencias que las presencias. En cuanto a los "clásicos" de la disciplina en España sólo se destaca a Severino Aznar ${ }^{11}$, mientras que de los sociólogos contemporáneos a la publicación del libro se hace más un recuento que una selección basada en algún criterio. Se olvida pues a Ortega y Gasset, Sales y Ferré, Posada, etc.

Como decíamos, la tesis que de Miguel sostiene en Sociología y subversión, y que de alguna manera coincide con la del libro Sociología española de los años '70, implica dos aspectos: una determinada concepción de la sociología y una determinada concepción de la historia de España. Esta manera de interpretar la historia de España a la que nos referimos se basa en la atipicidad de este país (Spain is different), en su incapacidad para alcanzar la modernidad, que sólo llegaría alrededor de los años sesenta del siglo XX, con cierto retraso, pues, respecto al resto de Europa, y que encaja perfectamente con la importación en esa década de la "sociología científica moderna" (dado que según la tesis de A. de Miguel, la sociología sólo se puede desarrollar en una sociedad moderna, y según el mismo autor sólo se alcanzaría la modernidad plena en la fecha señalada) ${ }^{12}$.

Igual que las narrativas egocéntricas, pero de manera más mecánica, en tanto en cuanto se considera que no ha habido sociología en el pasado porque no

\footnotetext{
${ }^{10}$ VVAA, Sociología española de los años '70, Confederación española de cajas de ahorros, Madrid, 1971. P. 22.

${ }^{11}$ De quien se dice que es "uno de los prohombres (si no el fundador) de la sociología española". Íbid. P. 17.

${ }^{12}$ No cabe aquí una discusión sobre la interpretación de la historia de España sostenida por estos autores. No obstante, Fusi ha venido publicando una serie de trabajos en los que se sostiene la normalidad de la historia de España, en lugar de abundar en su atipicidad. Como escribe Fusi "España venía experimentando un nada desdeñable proceso de modernización, crecimiento urbano y desarrollo industrial desde las últimas décadas del siglo XIX (que iba a prolongarse de forma más o menos sostenida hasta finales de la década de 1920)" (Fusi, 1999: 14; véanse también: Fusi y Palafox, 1998; Serrano Alcaide, 1998: 371). Los propios protagonistas del primer tercio de siglo consideran que su generación es "normalmente europea" (Marichal, 1984: 214-215).
} 
era posible (no había modernidad en España), las narrativas proféticas se orientan hacia el futuro, desde un paradigma concreto, y confían en las posibilidades de una forma concreta de hacer sociología como solución para el desarrollo de la disciplina de aquí en adelante.

Las narrativas progresistas nos narran el desarrollo de la disciplina sociológica de una manera pluralista y mecánica, asumiendo elevados grados de autonomización del campo sociológico español. Es, por tanto, una narrativa que privilegia los factores internos de desarrollo de la disciplina, al tiempo que minimiza la importancia de la propia definición disciplinar. La historia funciona en términos de precedentes, de diversas escuelas o ideas que, pese a estar formuladas de manera deficiente $y$ no poder ser consideradas como propiamente sociológicas, abren diversas líneas de investigación que, a partir de ahora sí, serán agendas sociológicas de investigación. Las diferentes líneas pre-sociológicas dan lugar, de este modo, a programas de investigación sociológicos que deberán desarrollarse de ahora en adelante, o que vienen siendo desarrollados por algunos autores cercanos en el tiempo. Se trata, por tanto, de un tipo de narrativa más generosa, en tanto en cuanto considera otras opciones disciplinas, aunque lo que la caracteriza es su anti-clasicismo radical. Todo lo previo es pre-sociológico, independientemente del paradigma que se considere. Además la propia lógica de la historia relatada en términos de factores internos abre la posibilidad de plantear un futuro para la sociología lleno de esperanzar.

Las narrativas teleológicas nos cuentan, de manera cerrada y concluida, el presente como la culminación inevitable del pasado. El pasado, igual que en las otras tres narrativas vistas hasta ahora, es considerado como presociológico. Hay también generosidad y menor rigidez que en las narrativas egocéntricas o las proféticas en cuanto a considerar la pluralidad de opciones paradigmáticas (entendidas, eso sí, como manifestaciones pre-sociológicas). Lo que cambia aquí, con respecto a las narrativas progresistas, es que la historia se cuenta de manera más mecánica y como algo inevitable. La sociología actual, o las sociologías actuales, independientemente de sus orientaciones paradigmáticas, es el resultado inevitable de la combinación de factores internos y externos. Por tanto, el desenvolvimiento de la estructura social acompaña al desarrollo interno de la disciplina y conduce al resultado final de la sociología del presente. Lo que hay, por tanto, es el resultado inevitable de su propio desarrollo.

Podría decirse que la lógica anti-clasicista y sus tipos de narrativa (egocéntrica, profética, progresista, teleológica) son narrativas sobre la sociología española propias de la segunda mitad del siglo XX. El deslumbramiento por la modernización de España, la salida a otros países, la influencia de la sociología norteamericana, el desarrollo de la sociología profesional en España, así como otros factores, llevaron a una sobrevaloración del presente y al menosprecio del pasado. La propia lógica de las bandas y pandillas de académicos (a decir de Th. Scheff, 1995) parece que lleva aparejado el menosprecio sistemático de otras opciones paradigmáticas. La cuestión, más allá de los errores de omisión interesados, y más allá de la explicación histórica, trasciende los límites del juego académico, y lo convierte en un problema político de configuración de espacios de diálogo. 
El abrupto corte que la guerra civil, la represión franquista, la censura y el exilio supuso en la vida social y cultural española afectó también a la disciplina sociológica. La forma en que lo hizo tiene que ver con la manera de narrar su propia historia. La definición de la sociología como sociología moderna, vinculada fuertemente a la sociología norteamericana estructural-funcionalista y a los nuevos métodos de investigación social, generó una doble orientación. Por un lado, una orientación hacia el futuro, caracterizada por manifiestos programáticos y por estudios empíricos y teóricos sobre la sociedad española. Por otro lado, hay una orientación hacia el pasado, caracterizada, en aparente paradoja, por su desprecio. El interés por el pasado, de este modo, es en realidad un interés por el presente y el futuro. Las historias se escriben para impulsar el trabajo propio, el paradigma propio, y presentar los retos de futuro de la disciplina sociológica.

A esto hay que añadirle otra cuestión, cual es la natural inclinación de la disciplina sociológica a olvidar a sus propios clásicos, así como a proponer nuevos programas y agendas de investigación ${ }^{13}$. Esta es una afección (en el sentido de Merton, 1990) o una manía (en el sentido de Sorokin, 1964) común en la disciplina. Como escribió Ignacio Sotelo "la 'juventud' de la sociología es permanente, en cuanto cada generación rechaza el pasado como precientífico" (1973: 63). Podríamos decir que forma parte de su programa genético, y probablemente tenga relación con las formas cambiantes que adopta su objeto de estudio. Por estas razones parece posible predecir que si bien algunas facetas de estas cuatro narrativas serán abandonadas en el futuro, es posible que se sigan escribiendo historias de la sociología que compartan algunas de estas dimensiones fundamentales. En todo caso, auguro dificultades serias para estas líneas de trabajo, dado el desarrollo de la autoconciencia de la comunidad sociológica española, así como dado también el desarrollo de la propia disciplina desde la segunda mitad del siglo $\mathrm{XX}^{14}$.

\section{¿La historia de un éxito?: narrativas con final feliz}

Dentro de esta línea encontramos a las narrativas con final feliz que presentan la historia de la sociología española en función de los hitos y acontecimientos institucionales. Esta forma de contar la historia dedica un esfuerzo considerable a investigar la recepción de la sociología en las universidades españolas. En ocasiones, se dejan de lado los autores no vinculados con las instituciones, aunque pueden participar como actores secundarios (o pueden ser transferidos fácilmente a cualquier otra disciplina). La obsesión por lo que podríamos llamar una búsqueda de "pureza institucional" lleva también a no considerar con el mismo rango a los autores que enseñaban sociología desde una cátedra compartida o mixta, por no hablar de quienes enseñaban y escribían sociología desde otras cátedras. Al parecer, ser catedrático de sociología y ética no es igual de relevante que serlo simplemente de sociología. Hay, desde luego, en este tipo de narrativas una suerte de teleología que olvida los contextos del

\footnotetext{
${ }^{13}$ Me he ocupado en otros lugares de esta manía, del eterno alumbramiento de la sociología (Ribes, 2005/2006 y 2007).

${ }^{14}$ No obstante, el desarrollo de la sociología en España desde finales del siglo XIX hacía también difícil plantear este tipo de narrativas, y, sin embargo, ahí están. Por tanto, conviene no considerar este tipo de narrativas como algo exclusivamente del pasado, ni vincular la existencia de sociología con narrativas que narran su existencia.
} 
pasado y no tiene en cuenta las peculiaridades propias de tales periodos, además de no tener en cuenta, en suficiente medida, lo que sucedía en otros países. Desde un presente de sociología institucionalizada se mira al pasado buscando institucionalización. Este tipo de narrativa funciona como fondo de numerosas visiones panorámicas que, de una u otra manera, emplean estos hitos institucionales como referentes claves, aunque después vayan añadiendo algunos elementos "heterodoxos". Tal vez los textos más relevantes de esta narrativa sean las contribuciones de del Campo en el libro que él mismo coordina sobre la historia de la sociología española (del Campo, 2001; "Introducción" y "El renacer de la sociología española 1939-1959"). En esos textos Del Campo expone, lo que podría denominarse, su teoría de la triple institucionalización de la sociología en España. En ella, se habla de los dos primeros intentos frustrados (Sales y Ferré, Aznar) y del tercero que acabó teniendo éxito (Arboleya). El criterio clave es el logro de la institucionalización. Y el éxito es el triunfo de la sociología institucional, con facultades y cátedras. La ventaja que tienen este tipo de narrativas es que son historias con final feliz, ya que la sociología está convenientemente institucionalizada, hoy en día, en España.

Las narrativas caracterizadas por su anti-clasicismo anunciaban el comienzo de un futuro inmediato prometedor (tras una ojeada a un pasado caracterizado como pre-sociológico), y, por tanto, funcionaban de una manera que podría caracterizarse como progresistas, puesto que, gracias al trabajo y empeño de unos cuantos sociólogos del presente la sociología iba por fin por el camino adecuado hacia un futuro, sin duda, mucho mejor. El paraíso sociológico reside, pues, en el futuro. En cambio, la narrativas institucionalistas retratan un presente ya pleno (con la institucionalización lograda) y dan la impresión de requerir solamente un esfuerzo por conservar lo logrado, por mantener los éxitos. La institucionalización, una vez conseguida, solamente puede mover hacia un intento de expansión y colonización en universidades y facultades. Una expansión administrativa, a fin de cuentas, sería tal vez el único futuro alentador. El paraíso sociológico está ya en el presente.

\section{Entre la custodia de lo sagrado y las formas sociológicas}

Compartiendo la inclusividad, la apertura y la ausencia del menosprecio como elementos fundamentales diferenciadores con respecto a las previas narrativas, hay dos espacios narrativos posibles. Las hemos denominado narrativas abiertas y narrativas sacerdotales. Ambas comparten también, como es evidente, un escaso interés por reivindicar un paradigma particular y exclusivo, por lo que comparten una definición pluralista de la disciplina. La sociología es aquello que ha sido (Ferraroti, 1975), o sociología es lo que hacen los sociólogos (Moya) podrían ser los dos puntos de partida de esta orientación. Sin excluir ningún paradigma ni definición concreta de la disciplina, estas narrativas se distinguen por la consideración del grado de autonomización del campo sociológico, y por centrarse, en mayor o menor medida, en los factores internos o externos.

Las narrativas sacerdotales se corresponden como el "modo sacerdotal de hacer sociología" en la formulación de Friedrichs (1977). Serían narrativas que tienen por objetivo o como consecuencia la conservación del saber sociológico 
español. El campo sociológico es visto como sometido a fuertes interacciones con otros factores externos. De este modo las historias que se narran tienen en cuenta en buena medida los contextos socio-históricos, intelectuales e institucionales en los que se producen las teorías y se practica la sociología. Las sociologías del pasado se analiza teniendo en cuanta la sociología que el concreto momento histórico, intelectual, social y cultural permitía. La orientación es una orientación hacia el pasado, hacia la mayor comprensión de lo que se hizo y las razones de por qué se hizo.

Las narrativas abiertas tienen por objetivo analizar las formas sociológicas del pasado. Al centrarse en los factores internos, se multiplican los análisis de redes, intercambios intelectuales, etc. Estas narrativas están abiertas hacia el futuro en tanto en cuanto las formas previas de hacer sociología se consideran como hilos posibles sobre los que lanzar nuevos proyectos y agendas de investigación. Hay, por tanto, una dimensión profética (en el sentido mencionado más arriba) dentro de ellas. La historia de la sociología no es solamente un fin en sí mismo, sino una indagación en las identidades de la disciplina, en las líneas de trabajo previas que pueden abrir nuevas posibilidades. De algún modo, este tipo de análisis del pasado de la disciplina es moneda común en la disciplina sociológica cuando ésta no reflexiona sobre sí misma. Al investigar problemas sociales se indaga en el pasado de la tradición en busca de ideas y sugerencias para poder analizarlos. Incluso podría decirse que cada nueva línea de problemas exige, por un lado, una relectura de los clásicos centrales, y, por otro lado, una búsqueda de nuevos clásicos que se ajusten mejor a los temas, las formas, etc., de un nuevo programa de investigación ${ }^{15}$. La clave es que se toma en serio el pasado, sin una ambición meramente arqueológica, y también sin condescendencia, alejados tanto de dogmatismos paradigmáticos como de nostalgias infudadas. Ésta parece ser la forma más productiva de acercarse al pasado sin perder la ambición de encarar el futuro. Algo que, insisto, se practica - sin una ambición sistemática - con total normalidad cuando el objeto de estudio es diferente a la propia historia de la disciplina.

\section{Para concluir: la paradoja de narrar lo que no ha sido}

Hay también que hacer referencia, como decíamos al comienzo, a una dimensión transversal de buena parte de las narrativas elaboradas sobre la sociología española. Se trata del curioso hecho de elaborar historias de la sociología española para concluir que prácticamente no existe la sociología española clásica. Pongamos dos ejemplos. Amando de Miguel se plantea como objetivo de Sociología y Subversión (1974) estudiar la historia de la sociología española, y, sin embargo, considera que no existe "sociología auténtica" hasta los años sesenta del siglo veinte. En el libro Historia de la sociología española, coordinado por Salustiano del Campo hay varios ejemplos significativos. Por citar uno, en dicho libro vemos cómo Gaspar Mairal se ocupa de la obra de Joaquín Costa. Según Mairal: "es difícil presentar a Costa como un sociólogo en sentido estricto, ya que no se propuso explícitamente el objetivo de

\footnotetext{
${ }^{15}$ Valga como ejemplo de esta búsqueda de nuevos clásicos la abierta reivindicación de Adam Smith y William James que hace Barbalet (2001), pretendiendo fundamentar su sociología de las emociones.
} 
desarrollar una obra sociológica" (Mairal, 2001: 62). Sin embargo, y al menos, según Mairal "dejó páginas brillantes para la historia, entre otras disciplinas, de la sociología y la antropología social españolas" (Mairal, 2001: 81). Algo parecido sucede con el capítulo dedicado a Ortega y Gasset. Según valora Castillo: "no hay sociología sensu stricto en la obra de Ortega" (Castillo, 2001: 133). Sin embargo, matiza Castillo: "en la voluminosa y variada obra de Ortega hay mucha y buena sociología, ya esté o no ligada formalmente a su teoría filosófica, por un lado; ya sea o no estrictamente científica, de otro. Lo que pasa es que la sociología que Ortega prodiga, de forma dispersa e intermitente, en sus libros, ensayos, artículos de periódicos y cursos es - a mi juicio - del tipo de sociología humanista que tan difícil resulta de diferencias de la filosofía social o del simple ensayo, pero que tanto hizo, practicada por los founding fathers - en particular por Simmel o Weber -, por la consolidación y avance de nuestra disciplina" (Castillo, 2001: 133). Es desde luego paradójico estudiar la historia de la sociología española cuando se considera que no existe tal cosa, o estudiar la sociología de un autor dentro de un libro de historia de la sociología que resulta no haber hecho sociología.

Las historias de la historia de la sociología española están escritas desde los diversos presentes inevitables que sus autores habitan. En dichos presentes es tan importante el momento histórico como el paradigma desde el que se escribe. En estas páginas he tratado de mostrar los diferentes espacios narrativos posibles, haciendo también referencia a algunos de los problemas básicos que las narrativas más influyentes de la historia de la sociología española han mostrado. A estos problemas habría que añadir las importantes lagunas en cuanto al género y la masiva desatención a las sociologías más heterodoxas.

La combinación de narrativas sacerdotales y abiertas parece, a mi juicio, el medio de expresión más adecuado para el desarrollo futuro de narrativas sobre la disciplina sociológica en España. Evitar la tentación a sobrevalorar la institucionalización, así como tratar de atender a las motivaciones, al juego de definiciones compartidas y denominaciones (incluyendo las autodenominaciones) de los actores implicados en el campo sociológico español parece una buena alternativa a aplicar exclusivamente nuestra subjetividad paradigmática a la hora de decidir quién tiene derecho a aparecer en una historia de la disciplina. Y, por último, parece también imprescindible renunciar definitivamente a la paradoja de narrar lo que no ha sido. Lo interesante no es examinar el pasado con la intención de encontrar lo que uno hace en el presente, sino con la intención de analizar las diversas formas de hacer sociología, por muy alejadas que estén de nuestra propia definición de la sociología. 


\section{Bibliografía}

Barbalet, J. M. (2001) Emotion, Social Theory and Social Structure: A Macrosociological Approach. Cambridge: Camridge University Press.

Campo, S. del (2001), Historia de la sociología española, Ariel, Barcelona.

- (2001), "El Renacer de la Sociología Española (1939-1959)" en del Campo (dir.), Historia de la Sociología Española, Ariel, Barcelona.

Castillo, J. (2001) "Ortega y Gasset y sus discípulos", en del Campo, S., Historia de la Sociología Española. Barcelona: Ariel.

Ferraroti, F., (1975 [1974]), El pensamiento sociológico de Auguste Comte a Max Horkheimer, Península, Barcelona.

Friedrichs, (1977), Sociología de la Sociología, Amorrotu, Buenos Aires.

Fusi, J. P., (1999), Un siglo en España. La cultura. Marcial Pons, Madrid y Barcelona.

Fusi, J. P., y Palafox, J. (1998) España 1808-1996. El desafío de la modernidad, Espasa, Madrid. (capítulos 4: "La restauración y el reinado de AlfonsoXII, 1874-1931"; y 6: “Dictadura, República, Guerra Civil, 1923-1939”).

Levine, D. (1995) Visions of the sociological tradition, The University of Chicago Press, Chicago.

Mairal, G. (2001) "Joaquín Costa y sus mundos", en S. del Campo (Coord.), Historia de la sociología española. Barcelona: Ariel.

Marichal, J., (1984), Teoría e Historia del ensayismo hispánico. Alianza Universidad, Madrid.

Merton, R. K. (1990) A hombros de Gigantes. Barcelona: Península.

Miguel, A. de, (1974) Sociología o subversión. Barcelona: Plaza y Janés.

Ribes Leiva, A. J. (2005) El enfoque sociológico en la producción intelectual de Francisco Ayala: una sociología de la sociología. Tesis Doctoral, Universidad Complutense de Madrid.

- (2005/2006) “El enfoque y la tradición sociológica”, en Sociológica, № 6.

- (2007) Paisajes del Siglo XX: Sociología y Literatura en Francisco Ayala. Madrid: Biblioteca Nueva.

- (2008) "Conocer a los que conocen: sociologías de las sociologías", en Revista Española de Investigaciones Sociológicas, №121.

- (2008b) “Luis Recaséns Siches y la sociología”, en A. J. Ribes Leiva (ed.) Luis Recaséns Siches. Madrid: Agencia Española de Cooperación Internacional.

Rodríguez Ibáñez, J. E. (2008) Voces cruzadas. Madrid: Biblioteca Nueva.

Rodríguez Ibáñez, J. E. (2011) "La Sociología española, 1959-2009: un análisis generacional", Documentos de Trabajo de Sociología en lengua castellana (DTSC), 1.

Romero Ramos, H., (2004), "Vivir en reductos. Una lectura de la obra de Enrique Tierno Galván (1918-1986)", en Política y Sociedad (Sociólogos españoles de posguerra), 41, Num. 2. 
Sarabia Heydrych, B., (2001), "Precursores de la sociología española. Siglo XX", en Salustiano del Campo (dir.) Historia de la Sociología Española. Barcelona: Ariel.

Scheff, Th. (1995) "Academic gangs", en Crime, Law and Social Change, 23.

Seffer, R. N., (1982), "Why do disciplines fail? The strange case of british sociology", en The English Historical Review, 97, pp. 767-802.

Serrano Alcaide, C., (1998), "Recensión a Fusi y Palafox, España 1808-1996", en Revista de Estudios Políticos, №102, Oct/Dic.

Sorokin, P., (1964), Achaques y manías de la sociología moderna y ciencias afines. Madrid: Aguilar.

Sotelo, I., (1973), "Sobre la institucionalización de la sociología en España", en Sistema, ํㅡ.

Torres Albero, C., (1994), "La sociología de la sociología", en Lamo de Espinosa, Gónzalez García y Torres Albero, La sociología del conocimiento y de la ciencia. Madrid: Alianza Universidad.

- (2002), "Notas sobre la evolución y el papel de la sociología de la sociología", en VVAA, La sociedad: teoría e investigación empírica. Libro homenaje a José Jiménez Blanco. Madrid: CIS.

V.V.A.A., (1971), Sociología española de los años '70. Madrid: Confederación Española de Cajas de Ahorros.

Zarco, J., (1999), "Notas sobre el Instituto de Reformas Sociales y las tres historias de la sociología española", REIS, ㄲ86, Abril-Junio.

- (2001), "El funcionalismo y la 'sociología empírica', en Del Campo, S., Historia de la Sociología Española. Barcelona: Ariel. 